\title{
Celiac Disease in Course of Lymphocytic Colitis in Children
}

\author{
Urszula Grzybowska-Chlebowczyk ${ }^{1}$, Maciej Kajor ${ }^{3}$, Sabina Więcek ${ }^{1, *}$, Joanna Kowol², Wojciech Chlebowczyk, \\ Halina Woś ${ }^{1}$ \\ ${ }^{1}$ The Department of Pediatrics, Medical University of Silesia, Katowice Poland \\ ${ }^{2}$ Gastroenterology Department, Upper-Silesian Child Health Care Center, Katowice, Poland \\ ${ }^{3}$ The Department of Pathomorphology, Medical University of Silesia, Katowice, Poland \\ ${ }^{4}$ The Department of Nursing and Social Medical Problems, Medical University of Silesia, Katowice, Poland \\ *Corresponding author: sabinawk@wp.pl
}

Received August 05, 2014; Revised September 11, 2014; Accepted September 20, 2014

\begin{abstract}
Lymphocytic colitis belongs to the group of microscopic colitis and it was first described in 1989 by Lazenby. Diagnosis is confirmed by histopathological examination, which shows characteristic changes in the form of chronic inflammation with increased number of intraepithelial lymphocytes, more than 20/100 epithelial cells. The aim of this study was a retrospective analysis of the clinical course of lymphocytic colitis and coexisting diseases, including celiac disease, in children and adolescents. The retrospective analysis included 52 children with lymphocytic colitis, hospitalized in the Gastroenterology Department, Department of Pediatrics Medical University of Silesia Katowice. Lymphocytic inflammation of the upper gastrointestinal tract, manifested in the form of lymphocytic infiltration (> 30/100 enterocytes) associated with villi damage and crypt hypertrophy, occurred in 10 patients (19\%).The occurrence of lesions in the upper gastrointestinal tract significantly correlated with the clinical manifestation of lymphocytic colitis, and was predominant in the group of older children. Despite, microscopic colitis is rare in children, it may be important to think of it in this group of age. The clinical picture and etiology of lymphocytic colitis in children, in many cases, is different than in adult. Celiac disease seems to be more prevalent in children with lymphocytic colitis.
\end{abstract}

Keywords: lymphocytic colitis, children, celiac disease

Cite This Article: Urszula Grzybowska-Chlebowczyk, Maciej Kajor, Sabina Więcek, Joanna Kowol, Wojciech Chlebowczyk, and Halina Woś, "Celiac Disease in Course of Lymphocytic Colitis in Children." International Journal of Celiac Disease, vol. 2, no. 3 (2014): 100-104. doi: 10.12691/ijcd-2-3-7.

\section{Introduction}

Lymphocytic colitis belongs to the group of microscopic colitis and it was first described in 1989 by Lazenby [1]. Typical symptoms of lymphocytic colitis are: a chronic watery diarrhea, accompanied by abdominal pain and weight loss, sometimes fecal incontinence, fecal urgency and nausea.

None macroscopic abnormalities of the mucosa are usually observed in colonoscopy. Diagnosis is confirmed by histopathological examination, which reveals characteristic, chronic inflammatory lesions with increased intraepithelial lymphocytes, more than 20/100 epithelial cells in the lamina propria. The lesions usually occur in the right part of the large intestine [2,3]. An atypical course of disease, which meets only the histopathological criteria, has been also increasingly reported. In these cases, there may be other clinical symptoms and macroscopic changes in colon mucosa.

Etiology of microscopic colitis is still unclear. Due to reports regarding coexistence of microscopic colitis and autoimmune diseases, such as: thyroid conditions, diabetes, celiac disease, psoriasis or rheumatic diseases, as well as family history of autoimmune diseases, the immunological background is suggested [4]. Significant influence of medication on disease development has also been described; especially non-steroidal anti-inflammatory drugs, proton pump inhibitors, carbamazepine, ticlopidine or ranitidine $[5,6]$. The impact of intestinal infectious diseases and diet to the disease manifestation has also been suggested [7].

It is mainly a condition of the middle age woman. There are no studies analyzing so large populations of children with lymphocytic colitis. There are some publication suggesting increase population incidence of lymphocytic colitis and assotiation with celiac disease $[8,9]$.

\subsection{Aim of Study}

The aim of this study was a retrospective analysis of the clinical course of lymphocytic colitis and coexisting diseases, including celiac disease, in children and adolescents.

\section{Patients and Methods}


The retrospective analysis included 52 children with lymphocytic colitis, hospitalized from 2004 to 2012 in the Gastroenterology Unit, Department of Pediatrics Medical University of Silesia in Katowice. The examined population consisted of 32 girls and 20 boys at the ages of 3-18 years (mean age 13.4 years).

Group I consisted of 12 children (4 boys and 8 girls) at the ages of 3-11 years (mean age 8.8 years). Group II consisted of 40 children (16 boys and 24 girls) at the ages of 12-18 years (mean age 15.1 years). On the basis of clinical symptoms in each patient, colonoscopy with mucosa biopsies from every part of the large intestine (despite lack of pathological lesions) was performed. On the base of the results of histopathological examinations in all examined patients, the diagnosis of chronic microscopic colitis - lymphocytic was made (chronic inflammation with increased number of intraepithelial lymphocytes more than 20/100 colonocytes). All children underwent upper gastrointestinal endoscopy with biopsies taken from the oesophagus, stomach and duodenum. Histopathological examination was evaluated using Sydney scale; duodenal biopsies were examined using modified Marsh Classification [10,11].

In all children the following tests were also performed:

- total IgE levels determined by chemiluminescence

Standards for age:

0-2 of age $<64 \mathrm{IU} / \mathrm{ml}, 3-5$ of age $<119 \mathrm{IU} / \mathrm{ml}, 6-15$ of age $<150 \mathrm{IU} / \mathrm{ml}$, above 15 years of age $<150$ $\mathrm{IU} / \mathrm{ml}$

- specific IgE for selected food allergens (milk, wheat flour, egg white and egg yolk) determined by chemiluminescence. Standard < 0,35kU/l.

- total IgA and IgG by immunoturbidimetric method (standards for age)

- tTG IgA levels by ELISA (Standards: <20EU/ml) or IgA EMA by indirect immunofluorescence (at low values for age the total IgA, tTG IgG or IgG EmA were taken).

The laboratory tests were performed in the Department of Laboratory Diagnostics, Upper-Silesian Child Health Care Center in Katowice.

A descriptive and statistical analysis of obtained results was performed. The statistical analysis was based on procedures available in MedCalc software. As arithmetic mean and standard deviation or median and interquartile range quantitative variables were presented. Qualitative variables were presented as absolute values and percentage. Distribution of normality was verified with Kolmogorov- Smirnov test. Differences between groups in case of quantitative variables were verified using KruskalWallis test and in case of qualitative variables using chisquare test. The value of $\mathrm{p}<0.05$ was accepted as a criterion of statistical significance.

\section{Results}

\subsection{Clinical Symptoms of Lymphocytic Colitis}

In only half of the children the clinical picture of lymphocytic colitis was typical (watery diarrhea, weight loss, lack of inflammatory lesions in the intestines). In other cases there was diarrhea with blood and unspecific inflammatory lesions of colon mucosa.
Regardless of age, the most frequent symptom was abdominal pain. Chronic diarrhea and loss of weight were more frequent in older children, while bloody diarrhea was more common in young children. These values were not statistically significant.

\subsection{Gastrointestinal Tract Endoscopy}

Colonoscopy performed in the examined patients macroscopically showed uncharacteristic, slight lesions in the large intestine mucosa in the form of hypertrophic lymphoid nodules and blurred vascular pattern in 26 (50\%) cases. Polyp, anal fissure or hemorrhoids were found in the rectum in individual cases. Based on the diagnostic criteria, only in half of the examined cases no abnormalities were observed.

In the histopathological examination moderate inflammatory infiltration of mononuclears, mainly including more than 20 lymphocytes per 100 colonocytes and some plasmatic cells, were found in all children.

The inflammatory infiltration had a higher density in the subepithelial area. Structure, shape and outline of glandular ducts were normal. In all examined patients no thickening of the subepithelial collagen layer was observed. In 42 children infiltration with intraepithelial lymphocyte occurred throughout the large intestine and in 10 children (19\%) only on the right side of the bowel. (Figure 1).

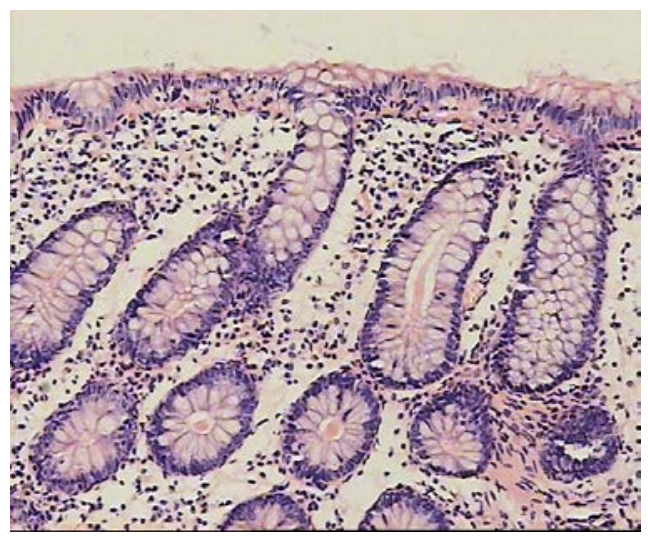

Figure 1. Lymphocytic colitis

Gastroduodenoscopy. Histopathological changes in the upper gastrointestinal tract in children with lymphocytic colitis were found in 40 children (77\%). Chronic, superficial gastritis was observed in 14 children (22\%), biliary gastritis in one child, and lymphocytic gastritis also in one. Chronic duodenitis was observed in 22 children (42\%), including 12 (23\%) with eosinophilic infiltration. Lymphocytic inflammation of the duodenum, in the form of lymphocytic infiltration more than 30/100 enterocytes associated with villi damage, crypt hypertrophy occurred in 10 patients (19\%).

Among these patients, in 6 patients (11.5\%) histopathological lesions corresponding to Marsh 3A were found, however, in only two cases celiac disease was confirmed by immunoassays (IgA tTG level was increased $>200 \mathrm{RU} / \mathrm{ml}$ ). The other 4 patient had normal level of tTG and normal level of IgA.

Statistically, inflammation in the upper gastrointestinal tract were significantly more frequent in the group of older children $(\mathrm{p}=0.03)$. 
In some children inflammation in both stomach and duodenum were observed (Table 1, Figure 2).

\begin{tabular}{|c|c|c|c|c|c|}
\hline Topography & Type of inflammation & $\begin{array}{l}\text { Number of patients } \\
n=52\end{array}$ & $\begin{array}{c}\text { Group I } \\
\mathrm{n}=12\end{array}$ & $\begin{array}{c}\text { Group II } \\
n=40\end{array}$ & $\mathrm{P}$ \\
\hline Oesophagus & Chronic oesophagitis & 1 & 0 & 1 & \\
\hline \multirow[t]{3}{*}{ Stomach } & Chronic superficial gastritis & 14 & 1 & 13 & \\
\hline & Chronic superficial biliary gastritis & 1 & 0 & 1 & \\
\hline & Chronic lymphocytic gastritis & 1 & 0 & 1 & \\
\hline \multirow[t]{6}{*}{ Duodenum } & Chronic superficial duodenitis with eosinophilia & 12 & 1 & 11 & \\
\hline & Chronic superficial duodenitis & 10 & 4 & 6 & \\
\hline & Chronic lymphocytic duodenitis (Marsh 1) & 2 & 0 & 2 & \\
\hline & Chronic lymphocytic duodenitis (Marsh 2) & 1 & 1 & 0 & \\
\hline & Chronic lymphocytic duodenitis (Marsh 3A) & 6 & 1 & 5 & \\
\hline & Total & $\begin{array}{c}40 \\
77 \% \\
\end{array}$ & $\begin{array}{l}6 / 12 \\
50 \%\end{array}$ & $\begin{array}{l}34 / 40 \\
85 \% \\
\end{array}$ & $\mathrm{p}=0.03$ \\
\hline
\end{tabular}

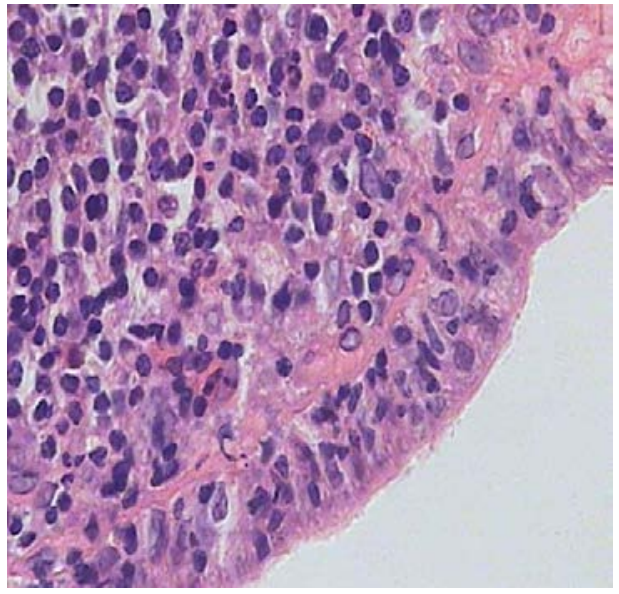

Figure 2. Lymphocytic infiltration in duodenum

Statistically, in children with lymphocytic infiltration involving the upper gastrointestinal tract, chronic diarrhea and loss of weight were significantly more frequent.

The occurrence of lesions in the upper gastrointestinal tract significantly correlated with the clinical manifestation of lymphocytic colitis, and was predominant in the group of older children.

\section{3. Analysis of Comorbidity}

In 13 patients (25\%) coexistence of IgE-mediated food allergy was observed, whereas airborne allergy in 6 children (11\%); food allergy, airborne allergy and atopic dermatitis coexisted in 21 (40\%) children. In children with lymphocytic infiltration in the upper gastrointestinal tract the incidence of food allergy was similar. Celiac disease was confirmed in two patients with lymphocytic colitis.

\section{Discussion}

Till now, in children lymphocytic colitis has been rarely described, usually as case reports [9,12] This disease usually affects people over 50 years of age, more often women (3:1). The estimated incidence is 4-6 cases per 100,000 yearly, and this tendency is growing [13]. Performed Cohort studies in Sweden, demonstrated a significant incidence of microscopic colitis among adults with prolonged diarrhea. The disease was confirmed in histopathological examination in $10 \%$ of study subjects.

The frequency of diagnosis increased with age, reaching $20 \%$ in subjects older than 70 years and the mean age of patients at the time of diagnosis for lymphocytic colitis was 59 years $[14,15,16]$.

Among the examined children, this disease mainly affected adolescents aged from 14 to 18, however at the time of diagnosis the youngest patient was 3 years old, and 4 children were below 10 . More than half of the patients were girls $(61,5 \%)$, it was similar to incidence observed for adult patients, and it is typical for other autoimmune diseases affecting children eg. celiac disease. [17].

Among the examined children, atypical clinical symptoms were frequently observed (e.g. bloody diarrhea); in half of the patients, uncharacteristic macroscopic lesions of the colon mucosa, including blurred vascular pattern and hypertrophic lymphoid nodules were found; this atypical form of disease only meets histopathological diagnostic criteria. Probably coexistence of diseases such as food allergy or bowel infections, could lead to atypical clinical symptoms. There is also a question, whether these diseases also induced lymphocytic colitis in the examined children.

Half of the children had a classic form of the disease, which met clinical, endoscopic and histopathological criteria. It should be noted that in the classic type of disease, infiltration consisting of intraepithelial lymphocytes is predominant on the right side of the large intestine and only biopsies obtained from this area (despite the absence of pathological lesions) enable to establish diagnosis. Results of rectal biopsies may be false negative in as many as $30 \%$ of patients [18].

This may explain the fact that in many patients the disease is not diagnosed. In all examined children, the whole colonoscopic examination, with biopsies taken from every part of the large intestine was performed, and in most patients lymphocytic infiltrate covered the entire colon while only in $19 \%$ it was observed in the right part of the intestine.

Etiopathogenesis of the disease is still unknown. Apart from genetic and immunological predisposition the influence of factors increasing intestinal wall permeability, leading to mucosa damage and immunological activation of Th1 and intraepithelial lymphocytes, are also taken into consideration in pathomechanism of lymphocytic colitis [19]. 
In 6 patients intestinal villi atrophy was observed, only in two cases celiac disease was confirmed by immunoassays. The coexistence of celiac disease and microscopic colitis is suggested in reports from other centers, studies in adults, and individual reports in children. Determination of HLA system in patients with lymphocytic colitis indicates that there is a statistically significant correlation between lymphocytic colitis and HLA DQ2, characteristic also for celiac disease. It supports the probability of genetic and immunological background of the disease. [20,21] The study conducted by Leeds, concerning the incidence of inflammatory bowel disease in patients with celiac disease, demonstrated lymphocytic colitis in $1.6 \%$ of cases [22]. In our study, celiac disease occurred in 2 (3.8\%) children, whereas in $19 \%$ of patients infiltration consisting of intraepithelial lymphocytes was observed in the upper gastrointestinal tract, with normal level of tTG antibodies. The incidence of celiac disease in most European countries is $1-2 \%$ of population, but this incidence could be twice higher.[17] Fine et al. demonstrated a high (30\%) incidence of celiac disease in patients with lymphocytic colitis. However, the author emphasized the necessity to differentiate lymphocytic infiltration in the intestinal mucosa as a complication of untreated celiac disease from lymphocytic colitis [23]. Both diseases are characterized by intraepithelial lymphocyte infiltration in various parts of the gastrointestinal tract. Increased number of intraepithelial lymphocytes in the cellular type of food allergy, chronic infection by Giardia lamblia, chronic hypogammaglobulinemia, and collagen diarrhea is also observed. Pathological lesions may occur in most of these diseases in both small and large intestine. It seems that morphology of intraepithelial lymphocytes in these diseases may result from T-cells reaction. Thus, in the absence of characteristic antibodies, we can consider another (not celiac disease) cause of intraepithelial lymphocyte infiltration. [24,25,26] Ozturk et al. described a child, in whom lymphocytic colitis was diagnosed when diarrhea did not finish despite gluten-free diet [12]. Regarding the study group, lymphocytic infiltration in the upper gastrointestinal tract may indicate immunological background of this disease and may suggest that lymphocytic colitis is a disease affecting not only the large intestine, but in many cases the whole gastrointestinal tract. Similar observations have been reported by $\mathrm{Wu}$ and Hamilton, as well as Najarian et al. [24,27] This may be supported by the coexistence of food allergy (result of disturbed immunological barrier of the intestines) in 25\% patients in the study group. Statistically, inflammatory lesions in the upper gastrointestinal tract were significantly more frequent in the group of older children and influenced on manifestation of clinical symptoms of this disease (diarrhea and loss of body weight). On the other hand, coexistence of other diseases could also influence on the presence of these clinical symptoms in investigated children.

There were no cases of long-term use of proton pump inhibitors, large doses of NSAIDs or other medicines influencing disease development in examined children. Taking into account a significant influence of medicines on manifestation of lymphocytic colitis in adults, the use of such medicines by children and adolescents could significantly increase the frequency of diagnosis in this group of patients. [28] In most of our patients, clinical symptoms disappeared following the initiation of the treatment by mesalasine, only one patient needed to use budesonide (with good results).

Crohn's disease developed in one boy.

\section{Conclusion}

Despite, microscopic colitis is rare in children, it may be important to think of it in this group of age. The clinical picture and etiology of lymphocytic colitis in children, in many cases, is different than in adult. Celiac disease seems to be more prevalent in children with lymphocytic colitis.

\section{References}

[1] Lazenby AJ, Yardley JH, Giardiello FM, Jessurun J, Bayless TM. "Lymphocytic ("microscopic") colitis: a comparative histopathologic study with particular reference to collagenous colitis.” Hum Pathol. 20(1). 18-28. 1989.

[2] Abdo A A, Beck P. "Diagnosis and management of microscopic colitis.” Can. Farm.Physician. 2003.49.1473-78.

[3] Liszka Ł, Woszczyk D, Pajak J. "Histopathological diagnosis of microscopic colitis.” J Gastroenterol Hepatol. 21(5). 792-7. 2006.

[4] Pardil DS, Ramnath VR, Loftus EV, Tremaine WJ, Sandborn WJ. "Lymphocytic colitis: clinical features, treatment and outcomes." Am. J. Gastrenterol. 97(11). 2829-33. 2002.

[5] Geramizadeh B, Taghavi A, Banan B. Clinical, endoscopic and pathologic spectrum of non-steroidal anti-inflammatory druginduced colitis. Indian J. Gastroenterol. 28(4). 150-3. 2009.

[6] Beaugerie L, Pardi DS. "Review article: drug-induced microscopic colitis - proposal for a scoring system and review of the literature.”Aliment Pharmacol Ther. 22(4). 277-84. 2005.

[7] Helal TE, Ahmed NS, El-Fotoh OA. "Lymphocytic colitis: a clue to bacterial etiology.” World J. Gastroenterol. 11(46). 7266-71. 2005.

[8] Kitchen PA, Levi AJ, Domizio P, Talbot IC, Forbes A, Price A. "Microscopic colitis: the tip of the iceberg? "Eur J Gastroenterol Hepatol 14.1199-204. 2002.

[9] El-Matary W, Girgis S, Huynh H, Turner J, Diederichs B. "Microscopic Colitis in Children". Dig.Dis.Sci 55.19962001.2010.

[10] Price A.B. “The Sydney System: Histological division.” J Gastroenterol Hepatol 6. 209-22. 1991.

[11] Oberhuber G, Granditsch G, Vogelsang H. "The histopathology of celiac disease: time for a standardized report scheme for pathologists.” Eur J Gastroenterol Hepatol 11. 1185-94. 1999.

[12] Ozturk Y, Soylu O, OzerE. "Lymphocytis colitis in a child with non-responsive celiac disease.” Acta Gastroenterol Belg 71(4). 393-510. 2008.

[13] Tysk C, Bohr J, Nyhlin N, Wickbom A, Eriksson S. "Diagnosis and management of microscopic colitis.” World J Gastroenterol 14(48). 7280-88. 2008.

[14] Olesen M, Eriksson S, Bohr J, Jarnerot JG, Tysk C. "Lymphocytic colitis: a retrospective clinical study of 199 Swedish patients.” Gut. 53(4). 536-41. 2004.

[15] Olesen M, Eriksson S, Bohr J, Jarnerot G, Tysk C.’Microscopic colitis: A common diarrhoeal disease. An epidemiological study in Orebro, Sweden, 1993-1998.” Gut. 53(3). 346-50. 2004.

[16] A. Sonnenberg, R. M. Genta "Lymphocytic and Collagenous colitis: Epidemiologic Differences and similarities.” Dig.Dis. Sci 58. 2970-2975. 2013.

[17] Fassano A, Troncone R, Branski D (eds) Frontiers in Celiac Disease. Pediatr Adolesc Med. Karger, Basel, 2008.12.18-22.

[18] Jaskiewicz K, Rzepko R, Adrych K, Smoczynski M. "Microscopic colitis in routine colonoscopies.” Dig-Dis-Sci. 51(2). 241-4. 2006.

[19] Geboes K. "Lymphocytic, collagenous and other microscopic colitides: pathology and the relationship with idiopathic inflammatory bowel diseases.” Gastroenterol. Clin.Biol. 32(8-9). 689-94. 2008. 
[20] Gillett HR, Freeman HJ "Prevalence of celiac disease in collagenous and lymphocytic colitis.” Can. J. Gastroenterol. 14(11). 919-21. 2000.

[21] Nyhlin N, Bohr J, Eriksson S, Tysk C. "Systematic review: microscopic colitis.” Aliment. Pharmacol. Ther. 23(11). 1525-34. 2006.

[22] Leeds JS, Horoldt BS, Sidhu R, Hopper AD, Robinson K, Toulson $B$ et al."Is there association between celiac disease and inflammatory bowel diseases? A study of relative prevalence in comparison with population controls.” Scan J Gastroenterol 42. 1214-1220. 2007

[23] Fine KD, Lee EL, Meyer L "Colonic histopatology in untreted celiac spurenor refractory spure: is it lymphocytic colitis or colonic lymphocytosis?” Hum Pathol 29. 1433-40. 1998.

[24] Najarian RM, Hait EJ, Leichtner AM, Glickman AJ, Antonioli DA, Goldsmith JD. "Clinical significance of colonic intraepithelil lymphocytosis in a pediatric population.” Mod.Pathol. 22(1). 1320. 2009.

[25] Rostami K, Kerckhaert J, Tiemessen R, von Blomberg BM, Meijer JW, Mulder CJ.”Sensitivity of antyendomysium and antygliandin antybodies in untreated celiac disease: disappointing in clinical practice.” Am. J. Gastroenterol. 94.888-894. 1999.

[26] Carmack SW, Lash RH, Gulizia JM, Genta RM: "Lymphocytic disorders of the gastrointestinal tract: a review for the practicing pathologist.” Adv. Anat.Pathol. 16(5). 290-306. 2009.

[27] Wu TT, Hamilton: SR. "Lymphocytic gastritis: association with etiology and topology.” Am. J. Surg. Pathol.Feb. 23(2). 153-58. 1999.

[28] Loftus EV. "Microscopic colitis: epidemiology and treatment." Am J Gastroenterol 98 (12supl.). 31-36. 2003. 